\title{
A ELIMINAÇÃO DAS DIFERENÇAS ENTRE OS SEXOS: UMA LEITURA PSICANALÍTICA
}

THE ELIMINATION OF THE DIFFERENCES BETWEEN THE SEXES: A PSYCHOANALYTIC READING LA ELIMINACIÓN DE LAS DIFERENCIAS ENTRE LOS SEXOS: UNA LECTURA PSICOANALÍTICA

\author{
Nádia Laguárdia de Lima* \\ Adilson Pereira dos Santos* \\ Alice Oliveira Rezende ${ }^{* * *}$ \\ Carolina Marra Melo ${ }^{* * * *}$ \\ Fabiana Cerqueira**** \\ Ronaldo Sales de Araújo ${ }^{* * * * *}$
}

\begin{abstract}
RESUMO
Este artigo apresenta o resultado parcial de uma pesquisa que teve como objetivo pesquisar as noçôes de feminilidade construídas pelas adolescentes na atualidade. Ele parte da hipótese de que o crescimento de grupos de adolescentes que se nomeiam bissexuais nas redes sociais da internet é resultado da ideologia atual de eliminação das diferenças entre os sexos. Utilizando o referencial teórico da psicanálise, consideramos essa ideologia de igualdade como um efeito do discurso capitalista, que visa a escamotear a castração. O declínio das diferenças entre os sexos coloca o adolescente com maiores dificuldades para situar-se como homem ou mulher no campo das identificações. Para além das várias máscaras identificatórias que buscam definir os gêneros sexuais, a psicanálise sustenta a existência de uma
\end{abstract}

Texto submetido em 18 de julho de 2013 e aprovado para publicação em 3 de agosto de 2015.

Professora adjunta do Departamento de Psicologia e do Programa de Pós-Graduação em Psicologia da Universidade Federal de Minas Gerais (UFMG). Endereço: Rua Professor Otávio Coelho Magalhães, 324 - Mangabeiras, Belo Horizonte-MG, Brasil. CEP: 30210-300. E-mail: nadia.laguardia@gmail.com.

* Psicólogo (PUC Minas); trabalha na Secretaria de Estado da Defesa Social do Estado de Minas Gerais, Brasil. Endereço: Avenida Albert Schwaitzer, 631, ap. 202 - Chácaras Califórnia, Contagem-MG, Brasil. CEP: 32042-330. E-mail: adilsonsantos@live.com.

*** Graduanda em Psicologia (UFMG), participante da pesquisa sobre o feminino nas redes sociais da internet (UFMG). Endereço: Universidade Federal de Minas Gerais, Faculdade de Filosofia e Ciências Humanas, Avenida Antônio Carlos, 6627 - Pampulha, Belo Horizonte-MG, Brasil. CEP: 31270-901. E-mail: aliceorezende@gmail.com.

**** Graduanda em Psicologia (UFMG), participante da pesquisa sobre o feminino nas redes sociais da internet (UFMG). Endereço: Rua Wilson Modesto Ribeiro, 180, ap. 707 - Ipiranga, Belo Horizonte-MG, Brasil. CEP: 31160-430. E-mail: melo. carolinamarra@gmail.com.

${ }^{* * * * *}$ Especialista em Teoria Psicanalítica (UFMG), participante da pesquisa sobre o feminino nas redes sociais da internet (UFMG); psicóloga da Prefeitura Municipal de Belo Horizonte, Brasil. Endereço: Rua Santa Rita Durão, 20, sala 608 - Funcionários, Belo Horizonte-MG, Brasil. CEP: 30140-110. E-mail: fabianaacer@gmail.com.

****** Mestrando em Psicologia (UFMG); psicólogo da Fundação Hospitalar do Estado de Minas Gerais, Brasil. Endereço: Fundação Hospitalar do Estado de Minas Gerais, Hospital Alberto Cavalcanti, Rua Camilo de Brito, 636 - Padre Eustáquio, Belo Horizonte-MG, Brasil. CEP: 30730-540. E-mail: rsales.psi@gmail.com.

Este artigo é parte da pesquisa intitulada: "Adolescência e contemporaneidade: a construção do feminino nas redes sociais da internet", coordenada por Lima, N. L., realizada na UFMG, com o apoio do Programa de Auxílio à Pesquisa de Doutores Recém-Contratados (PRPQ - UFMG), março 2013. 
diferença irredutível entre os sexos, que aponta para a impossibilidade da relação sexual.

Palavras-chave: Adolescência. Contemporaneidade. Sexualidade.

\section{ABSTRACT}

This article is the partial result of research aimed at investigating the notions of femininity constructed by teenagers. It starts from the hypothesis that the growth of groups of teenagers who call themselves bisexual in the social networks of the internet is a result of the current ideology elimination of the differences between the sexes. Using the theoretical framework of psychoanalysis, we consider the ideology of sexual equality with effect on the capitalist discourse that aims to conceal castration. The decline of the differences between the sexes puts the teenager in greater difficulty to situate themselves as male or female in the field of identifications. In addition to the various masks of identification seeking to define the genders, psychoanalysis supports the existence of an irreducible difference between the sexes, which points to the impossibility of sexual intercourse.

Keywords: Adolescence. Contemporaneity. Sexuality.

\section{RESUMEN}

Este artículo es el resultado parcial de una investigación cuyo objetivo fue conocer las nociones de feminidad construidas por los adolescentes en la actualidad. Él parte de la premisa de que el crecimiento de los grupos de adolescentes que se dicen bisexuales en las redes sociales es resultado de la ideología actual de eliminación de las diferencias entre los sexos. Utilizando el marco teórico del psicoanálisis, consideramos esa ideología de la igualdad como un efecto del discurso capitalista que trata de ocultar la castración. La disminución de las diferencias entre los sexos pone al adolescente con una mayor dificultad para situarse como hombre o mujer en el campo de las identificaciones. Más allá de las diversas máscaras identificativas que tratan de definir los géneros, el psicoanálisis sustenta la existencia de una diferencia irreductible entre los sexos, que apunta la imposibilidad de la relación sexual.

Palabras clave: Adolescencia. Contemporaneidad. Sexualidad.

\section{INTRODUÇÃO}

s noções de masculinidade e feminilidade são construídas socialmente.
$\mathrm{Na}$ Modernidade, os papéis sociais femininos e masculinos eram mais
claramente diferenciados. Os atributos considerados masculinos estavam
relacionados à força, virilidade e agressividade, e os femininos ligados à 
passividade, submissão e docilidade. A igualdade de direitos, um dos valores fundamentais da democracia, estende-se para uma ideologia da uniformidade, que alcança todos os setores da vida. É o que observamos no campo sexual. $\mathrm{O}$ importante movimento social em defesa dos direitos das mulheres alcança o campo das identidades sexuais, convertendo-se em uma apologia da igualdade sexual, que busca a condensação dos gêneros. Surge um descrédito com relação a todos os semblantes identitários. Contrária a essa ideologia social, a psicanálise defende a existência de uma diferença irredutível entre os sexos. A adolescência é um tempo lógico de encontro com o outro sexo, que exige do sujeito uma escolha de posição sexuada. Freud demonstra que o confronto com a castração exige do sujeito uma tomada de posição na partilha sexual, como homem ou mulher, a partir da referência fálica.

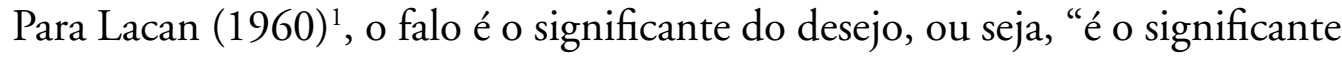
que dá a razão do desejo” (p. 700). O autor ressalta que o complexo de castração inconsciente tem uma função de nó, tanto na estruturação dos sintomas quanto na instalação, no sujeito, de uma posição inconsciente sem a qual ele não poderia identificar-se com o tipo ideal de seu sexo (p. 685). Cada sujeito assume seu sexo em função de sua relação com o significante da castração, o falo. A assunção subjetiva da diferença sexual é decisiva para a orientação sexual dos sujeitos.

Lacan (1960) substitui o "não ter" o falo do lado das mulheres, proposto por Freud, por "ser o falo". A falicização do corpo da mulher é uma solução que passa pela via da mascarada. No entanto Lacan reconhece algo de paradoxal nessa posição, pois, "para ser o falo, isto é, o significante do desejo do Outro, a mulher vai rejeitar uma parcela essencial da feminilidade, nomeadamente todos os seus atributos na mascarada" (p. 701). Essa parcela essencial da feminilidade aponta para o que é irrepresentável simbolicamente. Lacan reconhece que "a mediação fálica não drena tudo o que pode se manifestar de pulsional na mulher" (1960, p. 739). Existe, portanto, uma dimensão de gozo que não passa pela mediação do significante fálico.

Posteriormente, Lacan (1972-1973/1985) formula que as posições feminina e masculina implicam duas modalidades de gozo, fálico e feminino. A mulher experimenta um gozo que, em parte, está referido ao falo e, em parte, não pode ser simbolizado. $\mathrm{O}$ gozo feminino aponta para um impossível de simbolizar. $\mathrm{O}$ impossível se situa no nível da diferença sexual. Se não existe um significante, no inconsciente, que designe o ser mulher, cada adolescente busca, na cultura, um significante que designe o feminino, como forma de situar-se no campo das identificações. Essa solução é sempre insatisfatória, já que o feminino não pode

\footnotetext{
A primeira data indica o ano de publicação original da obra, e a segunda, a edição consultada pelo autor. Esta somente será pontuada na primeira citação da obra no texto. Nas seguintes, será registrada apenas a data de publicação original.
} 
ser simbolizado. Nenhuma identificação o é. No entanto, a identificação permite certo apaziguamento da angústia diante do confronto com a impossibilidade simbólica na puberdade. O ideal social atual de apagamento das diferenças sexuais deixa o adolescente com maiores dificuldades para situar-se como homem ou mulher no campo das identificações. Diante desse impasse social, surgiu o nosso interesse em investigar as noções de feminilidade construídas pelas adolescentes hoje.

\section{A METODOLOGIA DE PESQUISA}

Utilizamos, como método, a pesquisa qualitativa. Buscamos ler alguns escritos de adolescentes do sexo feminino nas redes sociais da internet para conhecer os significantes que elas utilizam para dizer do feminino, quais as soluções que elas constroem no campo das identificações para construir uma identidade supostamente feminina. Nesse sentido, no primeiro momento da pesquisa, fizemos uma leitura das narrativas de adolescentes do sexo feminino de diferentes redes sociais da internet, abertas ao público, selecionadas por meio de amostra não probabilística. Para selecionar as redes sociais, utilizamos as palavras-chave: adolescência, sexo, feminino, feminilidade, mulher. Selecionamos três grupos de identificação sexual, com base na maior frequência desses grupos nas redes sociais pesquisadas. O primeiro grupo, formado por adolescentes que assumem os semblantes tradicionalmente considerados masculinos, como os de força e virilidade; o segundo grupo, que defende as diferenças entre os sexos, buscando definir o que é feminilidade; e o terceiro grupo, formado por adolescentes que se nomeiam bissexuais, que defendem a ideia de que todas as pessoas são bissexuais, abolindo qualquer diferença entre os sexos.

No segundo momento da pesquisa, selecionamos três redes sociais de adolescentes do segundo grupo, que escrevem sobre o que é ser mulher hoje. Nessas redes, as adolescentes se correspondem com outras adolescentes, dando dicas, conselhos, compartilhando fotos, imagens, além de sentimentos e experiências pessoais. Buscamos investigar as noções que as adolescentes constroem sobre feminilidade nessas redes sociais. Nesses grupos, as adolescentes buscam circunscrever o gênero feminino, diferenciando-o do masculino. Essa segunda etapa da pesquisa não está concluída. A análise dos dados está sendo feita com base na análise do conteúdo (Bardin, 2009; Laville \& Dionne, 1999) e na análise do discurso (Orlandi, 1999; Pêcheux, 1990), associadas às bases da psicanálise estruturalista (Lacan, 1998). Recortamos os principais temas abordados pelas jovens, os significantes privilegiados para dizer do feminino, além das questóes e perguntas que formulam sobre a feminilidade. Os resultados finais dessa pesquisa serão divulgados posteriormente. 
Para este artigo, buscamos refletir sobre os dados levantados na primeira etapa da pesquisa, mais especificamente sobre os grupos formados por adolescentes do sexo feminino que se organizam com base na nomeação "bissexual". Apesar de os blogs serem abertos ao público, optamos por preservar as identidades das adolescentes, ocultando todos os dados pessoais que possam identificá-las. Fizemos a leitura de oito redes sociais de adolescentes que se nomeiam bissexuais. No Yahoo Respostas, um adolescente de 14 anos, que não revela o seu nome nem o seu sexo, questiona: “Onde encontro garotos adolescentes bissexuais?". Uma série de adolescentes responde à sua pergunta, buscando informá-lo ou criticando-o. Uma adolescente de 13 anos, que usa um nome fictício e não publica a sua foto pessoal, escreve em seu blog que não sabe se é bissexual. Ela destaca que se sente atraída por meninos, mas que ficou com uma menina e gostou da experiência. Acrescenta que, depois de conversar com algumas pessoas que são bissexuais, acredita que ela também pode ser e pede opinióes de comentadores em seu blog. A comunidade do Facebook "Sou bissexual" tem 6.939 curtidas. Muitos adolescentes de 13, 14 e 15 anos publicam suas fotos pessoais e revelam suas identidades nessa comunidade. A comunidade "Meninas bissexuais" têm 8.561 curtidas. Em algumas redes sociais pesquisadas, as adolescentes comentam sobre um possível aumento de jovens bissexuais na atualidade, descrevem celebridades que assumiram sua bissexualidade e mostram a frequência com que o tema tem aparecido na mídia. Algumas adolescentes acreditam que o que existe hoje não é o aumento do número de pessoas bissexuais, mas a maior possibilidade de expressão dessas jovens.

Defendemos a hipótese de que "a possível expansão" desses grupos de adolescentes do sexo feminino nas redes sociais pode ser interpretada como o resultado da ideologia social atual de apagamento das diferenças entre os sexos. Para fazer essa discussão, apresentaremos inicialmente uma reflexão sobre a Contemporaneidade e seus efeitos subjetivos, dialogando com autores da psicanálise, da filosofia e da sociologia que analisam o tema, para, finalmente, analisar o conceito de feminino e sua relação com a adolescência.

\section{ALGUMAS REFLEXÕES SOBRE A CONTEMPORANEIDADE}

O contemporâneo coloca em ação uma relação especial entre os tempos. Ele marca uma articulação entre o passado, o presente e o futuro. $\mathrm{O}$ contemporâneo divide e interpola o tempo, estando à altura de transformá-lo e de colocá-lo em relação com os outros tempos (Agamben, 2009). Se a Contemporaneidade é o tempo atual, ele é, entretanto, o mais distante, e não pode, em nenhum caso, alcançar-nos, como comenta Agamben (2009). O autor define a 
Contemporaneidade como uma singular relação com o próprio tempo, que adere a este e, ao mesmo tempo, dele toma distância, por meio de uma dissociação e de um anacronismo. Para o autor, aqueles que se aderem perfeitamente à sua época "não conseguem vê-la" (p. 59). O autor postula que todos os tempos são obscuros para aqueles que nele estão inseridos. Assim, contemporâneo é aquele que sabe ver essa obscuridade, que sabe neutralizar as luzes que provêm da sua época para descobrir as suas trevas, "Não se deixa cegar pelas luzes do século e consegue entrever nessas a parte da sombra, a sua íntima obscuridade" (p. 64). A luz, que é o escuro do presente, ao projetar a sua sombra sobre o passado, pode tornálo capaz de responder às trevas do agora (Agamben, 2009). Assim, diante do desafio de dizer sobre o contemporâneo, elegemos alguns autores que enfatizam as relaçôes existentes, tanto de continuidade quanto de descontinuidade, entre o tempo atual e o precedente, enfatizando, entretanto, a impossibilidade de um rompimento absoluto com o passado. Como nos alerta Agamben (2009), buscamos não nos deixar cegar pelas luzes do nosso século, para descobrirmos as suas trevas.

As transformações ocorridas a partir do final do século XX em todo o mundo, nos campos político, social e econômico, repercutiram nas relaçôes sociais e nas subjetividades. Diversos autores do campo da filosofia, da sociologia e da psicanálise, passaram a questionar se tais mudanças se configurariam como uma nova forma social, que foi denominada por alguns de sociedade pós-moderna.

Não existe um consenso entre os autores que analisam a Contemporaneidade com relação à utilização do termo Pós-Modernidade para designar a época atual (Lima, 2003). Alguns autores definem o pós-modernismo como um movimento que se contrapõe ao modernismo, representando uma ruptura radical com o período precedente (Hassan, 1985, apud Harvey, 1992). Outros o caracterizam como uma versão do Modernismo, que remonta a uma corrente de pensamento moderno. Nietzsche já enfatizava o profundo caos da vida moderna e a impossibilidade de lidar com ele com o pensamento racional. Segundo Harvey (1992), a condição de fragmentação, efemeridade, descontinuidade e mudança caótica do pensamento pós-moderno representa uma continuidade do pensamento moderno, com uma importante diferença, a Pós-Modernidade aceita o efêmero e o fragmentário, não tentando transcendê-lo. Para Jencks (1989), o pós-modernismo é tanto uma continuação do modernismo quanto a sua transcendência. A sua característica é exatamente a amplitude de opções, conflitos e descontinuidade das tradiçôes, ou seja, uma heterogeneidade que capta nosso pluralismo.

Como processo histórico, pois, a Pós-Modernidade revela-se na convergência de vários outros momentos anteriores. As características que nos permitem 
diferenciá-lo de outras épocas da história da humanidade são, entre elas, as crescentes transformações nas relações humanas advindas de transformações econômicas, culturais e sociais, aceleradas pela globalização. Atribui-se a esse fato a influência das mídias como espaço de comunicação, o que permitiu ao homem a superação de fronteiras. Essas transformaçôes, além de permitir avanços, apresentam um rompimento com antigos referenciais humanos e em meio à construção de novos referenciais o homem contemporâneo vai tecendo sua existência.

Assim, consideramos como marca da Contemporaneidade o fenômeno da globalização, promovido pelo capitalismo e definido como o estabelecimento de uma rede de informaçóes a distância e de fluxo contínuo, que tem como suporte as tecnologias da informação, que organizam a vida econômica, política e social, segundo uma ordem mundial.

Por meio do computador, o homem pôde viver o fenômeno da transposição de fronteiras. Conectados, podemos agora superar os limites do tempo e do espaço, numa confluência de momentos e lugares que, do ponto de vista da Física, chamamos de tempo real, sendo que, do ponto de vista histórico, chamamos de interdependência e solidariedade do acontecer (Santos, 2011).

Tornamo-nos capazes de alcançar o conhecimento do outro lado do mundo. Com o surgimento da globalização, os produtos e serviços, antes comuns a uma determinada cultura, transcendem barreiras. No entanto, tal transposição das fronteiras trouxe maiores dificuldades na delimitação das fronteiras que separam o individual do coletivo, o público do privado.

O período atual permite o que nenhum outro período histórico ofereceu ao homem, ou seja, a possibilidade de conhecer o planeta extensiva e profundamente. Esse avanço do conhecimento permitiu a potencialização da capacidade criativa do homem, avançando na lógica de não utilizar somente os produtos que antes estavam à nossa disposição, mas lhe proporcionando a possibilidade de construção dos produtos necessários ao desenvolvimento de sua prática. Pelas ciências conectadas, universalizam-se conhecimentos, saberes e práticas.

Nunca se teve tanta informação em tempo real na história da humanidade. Entretanto esses avanços da globalização trouxeram consequências para os modos de vida na Contemporaneidade. Presenciamos atualmente o culto pelo "ao vivo", pela notícia no momento mesmo em que acontece, no qual a informação se tornou um produto a ser consumido. Santos (2011) nos aponta que não há essa reflexão por parte de quem consome, pois estamos entregues à ideia de que consumimos verdades: 
Numa sociedade complexa como a nossa, somente vamos saber o que houve na rua ao lado dois dias depois, mediante uma interpretação marcada pelos humores, visões, preconceitos e interesses das agências. O evento já é entregue maquiado ao leitor, ao ouvinte, ao telespectador, e é também por isso que se produzem no mundo de hoje, simultaneamente, fábulas e mitos (p. 40).

Os indivíduos orientam suas ações para outros que não partilham o mesmo ambiente espaço-temporal, ultrapassando os limites de seus contextos e localizações. A possibilidade de transformação da vida cotidiana em eventos a serem transmitidos a espectadores é o que orienta as ações de indivíduos nos dias atuais.

A informação presente na Contemporaneidade é manipulada por aqueles que se apropriam e que são responsáveis por sua distribuição. Graças às notícias prontas para serem consumidas, os indivíduos deixam de lado o interesse pelo fato para serem reprodutores de informaçōes, num interminável jogo de telefone sem fio, no qual cada um dá a interpretação que quiser para o que se escuta. Todos escrevem, leem e compartilham as suas opiniōes. Não importa mais a veracidade das informações, todas se equivalem.

Com isso, surgem as falsas ideias de integração das ditas aldeias globais pelas facilidades de comunicação instantânea com qualquer lugar do planeta. As aldeias globais, na verdade, apontam para um paradoxo, pois, ao mesmo tempo em que interligadas, as pessoas se encontram cada vez mais isoladas em mundos próprios.

A competitividade está presente na Contemporaneidade como um valor. Ao mesmo tempo em que ela denota para a diferenciação entre as pessoas, sendo uma maneira de deixar a sua marca no mundo, a competitividade produz, como consequência, individualismos.

Seja na economia, resultado das lutas entre as empresas por capital, seja territorial, por meio da disputa por espaço de particularismos nas cidades ou nas relaçôes da ordem social em que o outro é tomado com coisa, o que percebemos é que a base da sociabilidade mediada na Contemporaneidade é a individualidade.

A lógica capitalista alimenta a competitividade, o individualismo e o consumismo. Como marca de nosso tempo, o consumo é um veículo de narcisismos, por meio dos seus estímulos estéticos, morais e sociais, e convertese no grande fundamentalismo da atualidade (Santos, 2011). Na atualidade, a figura do consumidor substitui a do cidadão, havendo um imperialismo dos objetos de consumo. Se, antes, tínhamos objetos que comandávamos, hoje 
somos comandados por esses objetos, a serviço do mercado. Nesse mundo, não é preciso conhecer o vizinho mais próximo. A interação social é mediada por objetos de conexão.

Destacam-se, segundo Bauman (2004), duas faces da mesma moeda que circula em nossos dias. Junto à ideia de proximidade virtual que as conexóes oferecem, existe uma distância virtual, que é a suspensão de qualquer fator que aponta para uma proximidade.

A realização mais importante da proximidade virtual parece ser a separação entre comunicação e relacionamento. A proximidade virtual aponta para um rompimento entre a comunicação e o relacionamento entre os indivíduos na Contemporaneidade. "Estar conectado" é menos custoso do que "estar engajado", mas também consideravelmente menos produtivo em termos da construção e manutenção de vínculos (Bauman, 2004, p. 39).

Por conseguinte, presenciamos hoje o enfraquecimento dos coletivos institucionalizados, o culto do individualismo temperado pelo surgimento de novos coletivos, a importância do sucesso, a pressão da urgência e a prioridade dada ao ato. Se em outros momentos as lutas de classe movimentavam as transformações e com isso os ideais dos indivíduos, o que percebemos hoje é o afrouxamento dos laços sociais.

O consumo, a globalização e a constituição da sociedade em rede inauguram, pois, uma nova lógica, marcada pela exacerbação do individualismo e pela horizontalidade das relaçôes. Essa nova lógica se consolida a partir do declínio das diferenças que até então sustentavam o mundo, entre elas o público e o privado, o próximo e o distante, o real e virtual. Os ideais sociais verticais que agrupavam os sujeitos são substituídos pelos objetos de consumo, que prometem a satisfação individual.

\section{ACONTEMPORANEIDADEESUASIMPLICAÇÕESSUBJETIVAS}

Lacan (1970/2003) utilizou o termo ascensão ao zênite social do objeto a para expressar que a sociedade caminha para uma lógica na qual o objeto a alcança seu ponto mais elevado e impera onde antes reinava o ideal. Segundo o autor, há "a ascensão ao zênite social do objeto que chamo pequeno a” (p. 411), que pode ser tomada como consequência do discurso capitalista. Ele se instala, portanto, no lugar em que o significante não consegue fornecer a fórmula da relação sexual. $\mathrm{O}$ termo carrega a ideia de que esse movimento está em andamento progressivo. A incidência das guerras mundiais, o fracasso das utopias comunitárias são eventos que convocaram sua ascensão, na medida em que provocaram a queda dos ideais 
e a desqualificação dos valores e ideais coletivos que organizavam a vida social (Laurent, 2007).

Se Freud localizava a causa das neuroses de sua época na repressão da sociedade, cuja intervenção tinha como objetivo adequar o sujeito às normas, a causa do malestar de hoje pode ser tomada como resultado da falta de referentes simbólicos que vinculem o sujeito à cultura, como observa Laurent (2007). Enquanto na estrutura patriarcal era possível se pensar numa distribuição igualitária do gozo, a ascensão do hedonismo com suas manifestações polimorfas expõe a impossibilidade de se ter esse acesso garantido (Laurent, 2007). Observamos, portanto, a cultura atual sendo guiada pela queda do ideal e pelo culto ao gozo que apaga, por assim dizer, a particularidade do sintoma.

A Revolução Francesa inaugurou a democracia, trazendo profundas mudanças à sociedade. Essa nova forma de governo, sustentada no discurso da ciência, reestruturou o laço social em uma nova ordem. Nela vivenciamos o fim da hierarquia, acusada por sustentar as desigualdades e a ocupação do lugar do mestre pela ciência, como sendo o "ao menos um" que escapou à castração. Esse movimento de recuo diante da castração foi acelerado pela sociedade de consumo.

A multiplicidade de ofertas de identificação afeta a estabilidade das identificaçôes, visto que não são mais reguladas pelo Ideal. O imperativo de gozo é acompanhado pela produção acelerada de S1. Essa produção massiva de S1 pode ser chamada de "nome para tudo" (Brodsky, 2011b). Assim, o outro lado do imperativo de gozo é o "nome para tudo", algo como um fundamentalismo da nominação. A Contemporaneidade não é marcada apenas pela produção de gadgets, mas pelo consumo de S1. Esses nomes surgem predominantemente da ciência, ou do "oceano de falsa ciência" (Brodsky, 2011b, p. 63).

No lugar do Ideal do Eu que está na origem da identificação, que gera certo ordenamento dos gozos, surge o "nomear para", que tem como uma das facetas o "ter um nome para tudo" (Brodsky, 2011b, p. 66). As comunidades se formam em torno de um nome comum, e não do nome próprio, impondo modos de gozo comum a todos, como comunidades de gozo. Como destaca Brodsky (2011b), esse nome comum não identifica alguém, como o nome próprio o faz, mas os mantêm anônimos, como os alcoólicos anônimos, jogadores anônimos, compulsivos anônimos, entre outros. Os sujeitos se agrupam em pseudoidentificações.

O discurso capitalista coloca o sujeito na posição de agente, mantendo-o na ilusão de que é ele quem comanda o discurso. No entanto ele é comandado pelo mercado, que promete a cura da sua divisão subjetiva pela via do acesso direto ao objeto. Goze! Esse é o imperativo social contemporâneo. 
A (in)satisfação que caracteriza a pulsão alimenta o mercado de produção com objetos cada vez mais descartáveis e evanescentes. Sob esse novo regime, somos submetidos a uma nova economia psíquica na qual o desejo cede lugar ao gozo.

Todas essas mudanças incidem sobre o sujeito e sobre a sua representação social. A noção de indivíduo se sobrepõe à de sujeito, já que remete a um ideal de indivíduo total, não dividido, que deve a todo custo realizar seus desejos e vontades, que são soberanas. Fazendo coro a esse discurso, há também as neurociências e demais correntes da psiquiatria, que reduzem o "bom funcionamento" do homem à utilização de medicamentos. Se existe alguma disfuncionalidade no homem, esta pode ser corrigida, já que é causada apenas por elementos externos que podem ser eliminados por intervençôes tão alheias a seu psiquismo quanto o mal que o causou (Kehl, 2007).

Para dar conta dessa forma de viver, o sujeito se afasta de tudo aquilo que pode perturbá-lo e incomodá-lo e assume para si uma forma de vida autônoma e independente. Como salienta Kehl (2007), tal sujeito, portanto, vive em constante crise, pois existe uma demanda endereçada a ele que o convoca a uma vida social intensa, caso contrário, estará excluído do laço social. Pensando em liquidar o mal-estar que lhe acomete, ele se submete às várias formas de espiritualidade alternativa que lhe aparecem ao longo do caminho, bem como às técnicas de "autoajuda".

As atividades que exigem renúncia ao gozo, esforço de conquista e adiamento da satisfação são, pois, desprezadas (Lima, 2009). Alternativas de tratamento, como a própria análise, são rechaçadas sob a justificativa da extensão do tempo e do gasto excessivo de dinheiro. Tais elementos são fundamentais à sobrevivência no mundo capitalista e não devem ser "desperdiçados". Ainda mais se pensarmos no alcance dos seus resultados que nem sequer são capazes de abolir completamente a angústia de existir (Kehl, 2007).

Para Bauman (2004), os sujeitos constroem identidades efêmeras e estabelecem laços sociais líquidos, visto que evitam as relações duradouras. Passam-se, portanto, por indivíduos sem características próprias e sem uma história de vida, pois se tornam apenas sujeitos do presente, sem passado ou expectativas para o futuro, em um mundo no qual reina uma eterna incerteza. Todas essas mudanças colhidas na Contemporaneidade incidem sobre as formações sintomáticas do sujeito.

Os efeitos de se viver imerso na cultura do consumo, na qual se percebe uma nova ordem simbólica, são colhidos no corpo. As patologias como as anorexias, bulimias, compulsões e depressões não são nada mais do que tentativas de se 
transmitir uma mensagem através de um corpo que se apropria cada vez menos da palavra para dizer do seu sofrimento.

Vivemos uma nova ordem simbólica (Brodsky, 2011a) que estabelece o declínio da hierarquia, a pluralização significante (S1), a igualdade de valores e que defende a felicidade como um bem geral, a ser alcançado por todos, pela via do consumo. Essa nova ordem de igualdade incide sobre o campo sexual, com efeitos na construção da identidade sexual dos adolescentes. Um grupo crescente de pessoas recusa a utilização de qualquer tipo de "classificação" ou categorização para as práticas e prazeres sexuais, justificada não só pelos efeitos excludentes e segregativos destas classificaçōes, mas, principalmente, pela crença num domínio absoluto sobre o gozo, numa sexualidade absolutamente livre, sem nenhum tipo de determinação, mesmo que inconsciente. Essa suposta liberdade, no entanto, esconde um repúdio à castração.

\section{A ADOLESCÊNCIA NA PSICANÁLISE}

A adolescência é uma construção social (Lima, 2009). A psicanálise compreende a adolescência como um tempo lógico de intenso trabalho psíquico, como resposta às transformações biológicas da puberdade.

Freud, em seu clássico texto Três ensaios sobre a teoria da sexualidade (1905/1974), articula a adolescência com o alcance da sexualidade genital e as transformações do corpo, acentuando as exigências psíquicas e o afrouxamento dos laços com os pais que ocorrem nesse momento da vida:

Contemporaneamente à suplantação e à rejeição dessas fantasias claramente incestuosas, produz-se o mais importante dos trabalhos psíquicos, mas também o mais doloroso da época da puberdade: o desligamento dos pais. Esse desligamento produz a contradição, tão importante para a evolução cultural, entre a nova geração e a antiga (p. 78).

A adolescência implica em uma desconexão no sujeito entre ser criança e ser adulto. É também o encontro do sujeito com o desejo sexual: a mudança da vida sexual infantil e da escolha do objeto de amor, ou seja, do autoerotismo para o encontro com o objeto sexual.

A escolha de objetos de amor é orientada pelo período da infância e renovada na puberdade, principalmente na tendência sexual da criança pelos pais e, ou, cuidadores. No tempo da adolescência, há um desvio desses sujeitos pela barreira do incesto que é construída na latência. O afeto pelos pais apontará o caminho para a escolha de objetos de amor na puberdade. 
Freud (1905) considera a tarefa do adolescente de separar-se da autoridade de seus pais e escolher uma posição sexuada como sendo um dos trabalhos psíquicos mais importantes e dolorosos no desenvolvimento psicossexual. $\mathrm{O}$ adolescente precisa abandonar os objetos de amor da infância, substituindo-os por novos objetos. Como assinala Cottet (1998), "o divisor de águas se faz muito claro entre os objetos sexuais e os pais" (p. 101). Desvincular da autoridade dos pais é abrir espaço para dois movimentos: o abandono dos objetos de amor da infância e o direcionamento para a busca de novos objetos amorosos e novos direcionamentos da libido. Para Freud, "A escolha de objeto da época da puberdade tem de renunciar aos objetos infantis e recomeçar com uma corrente sensual" (1905, p. 87).

No tempo da adolescência, há uma rápida transformação do corpo, que traz angústia, sendo um lugar de atualização do problema da identidade e do gozo indizível. A adolescência exige do sujeito um posicionamento sexual e uma escolha de objeto. $\mathrm{O}$ encontro com o real do sexo autoriza o sujeito a utilizar-se de seu corpo na prática sexual. O tempo de adolescer é o momento do florescer inevitável da sexualidade, que, segundo Freud, marcam a passagem do autoerotismo para a escolha objetal.

O corpo se transforma na puberdade, levando o sujeito a se deparar com o desconhecido (Lima, 2009). As palavras não dão conta de nomeá-lo, há um impossível de dizer. "A sexualidade faz um furo no real", como explica Lacan (1974/2003, p. 558) no prefácio de $O$ despertar da primavera. A sexualidade, para a psicanálise, é determinada com base na relação do sujeito com o Outro da linguagem, mas surge exatamente do impossível da linguagem.

A ruptura do ser criança leva o sujeito a se interrogar sobre o que é ser homem ou mulher. O seu corpo não produz respostas, e sim, questionamentos. É um momento delicado de transição, marcado por rupturas, que coloca o sujeito diante do impasse da inexistência da relação sexual. Nesse tempo lógico do despertar de um gozo que escapa ao sentido, surge o embaraço com relação à identidade sexual. As experimentações com os parceiros do próprio sexo são frequentes nesse momento, em especial, entre as meninas, que podem desfrutar do contato físico com as amigas com maior liberdade do que os meninos, em razão da maior repressão social imposta para os homens. Freud apontou que a pulsão sexual não tem um objeto fixo, a sexualidade humana é perverso-polimorfa. Assim, o contato físico com outra pessoa pode ser prazeroso, independentemente de seu sexo. Além disso, os investimentos libidinais nos progenitores do próprio sexo ocorrem desde a mais tenra infância e permanecem no inconsciente. Para Freud, a escolha de objeto sexual e de uma posição sexuada é um processo resultante das resoluções edipianas, ou seja, das relações simbólicas. A puberdade é o momento 
de reedição do Édipo, quando o sujeito terá a chance de refazer a sua escolha de posição e de objeto sexual. Para Lacan, a passagem pelo Édipo leva o gozo a adquirir uma significação fálica, mas o despertar dos sonhos, na puberdade, confronta o jovem com um gozo que extrapola o campo significante.

Em Televisão, Lacan (1973/2003) comenta que "o impasse sexual secreta as ficçôes que racionalizam a impossibilidade da qual provém” (p. 531). Assim, trata-se, no confronto com o real do sexo, de produzir ficções, que, entretanto, somente podem recobrir parcialmente o furo no real. $\mathrm{O}$ sujeito adolescente é levado a elaborar respostas para o mal-estar provocado pela irrupção do real e pela perda das referências de identificação construídas na infância. Para isso, ele se apoia nas ofertas da cultura. Ele se apoia em significantes que lhe garantem uma "identidade social". A formação de grupos é fundamental nesse momento. Os grupos se formam a partir de um significante comum, que os enlaça. São respostas que o ajudam a situar-se no campo do Outro. Surge, pois, a possibilidade de servir-se do significante bissexual ofertado pela mídia.

Discutiremos, a seguir, o feminino na psicanálise, para, finalmente, refletir sobre o que os escritos de adolescentes na internet nos ensinam sobre as suas escolhas no campo das identificações sexuais hoje.

\section{O FEMININO NA PSICANÁLISE}

Freud (1924/1974) nos esclarece que a diferença sexual não está situada no campo da biologia, apesar de o real da diferença anatômica entre os sexos incidir sobre a subjetividade. Para o autor, a criança, ao descobrir a diferença anatômica entre os sexos, diferencia o homem da mulher pela presença ou ausência do falo. Trata-se de ter o falo ou ser castrado. O inconsciente só reconhece a inscrição do falo como significante do sexo, o que coloca a mulher na condição de castrada. No entanto, para Freud, a ausência do falo na mulher poderia ser suprida com a maternidade, quando o filho passaria a ocupar o lugar do falo para a mulher. Para Lacan (1972-1973/1985), Freud permanece preso na referência fálica. A premissa fálica do inconsciente não reconhece a inscrição do Outro sexo, apenas do Um fálico. As mulheres são não todas fálicas, pois, em parte, estão referidas ao falo, mas, em parte, estão referidas a uma dimensão de exterioridade absoluta. No Seminário 20: mais, ainda, Lacan (1972-1973) diferencia as duas modalidades de gozo, masculina e feminina. A masculina está situada dentro da lógica fálica, e a feminina, para além do falo, como lugar da alteridade. $O$ feminino escapa à dialética masculina e evoca a dimensão do infinito. A diferença entre os sexos é, pois, situada, a partir da escolha de uma modalidade de gozo, o gozo fálico, masculino, ou o outro gozo, feminino. Não há uma igualdade entre os sexos, 
mas duas modalidades de gozo, não complementares entre si. Se "a mulher não existe", é porque ela somente existe como um dos nomes do real. A alteridade radical é o feminino. O gozo feminino não é privilégio das mulheres, mas evoca um gozo real indizível que afeta todo ser humano. Ele evidencia a dimensão não toda da linguagem, o real para além da linguagem, sem sentido algum.

Para Lacan (1972-1973), a mulher se inscreve no gozo fálico, ou seja, seu desejo é também orientado pelo falo simbólico. Mas ela também goza da ausência do significante, experimentando um gozo impossível de ser dito.

Se não há uma representação para o feminino no inconsciente, cada mulher constrói uma resposta frente a essa ausência. No lugar desse vazio do significante na mulher, no inconsciente, que a designe como tal, surgem distintas possibilidades de suplência (Brousse, 2001). As identificaçôes são respostas que permitem uma solução parcial ao enigma do feminino. Situadas dentro da lógica fálica, as identificações permitem certo apaziguamento da angústia que surge diante do confronto, na puberdade, com o gozo indizível, com a dimensão real do gozo. Se essa solução é parcial, é porque algo do real não se submete ao significante, exigindo uma resposta para esse impossível de simbolizar, que implica em saber operar com o vazio da castração.

\section{O IDEAL CONTEMPORÂNEO DE APAGAMENTO DAS DIFERENÇAS ENTRE OS SEXOS}

Os movimentos iniciados na internet reproduzem-se rapidamente, alcançando a adesão em massa, o que nos leva a considerar a força política das redes sociais. A posição defendida por muitas dessas jovens que se dizem bissexuais é a de que não há a necessidade de se fazer uma escolha de objeto sexual, nem de modo de gozo, pois "todos nós somos bissexuais". Algumas adolescentes escrevem na internet que, a partir da leitura dos escritos de outras adolescentes "bissexuais" nas redes sociais, elas começaram a questionar a sua identidade sexual, o que ilustra a influência da mídia sobre as identificaçooes no campo sexual. Godoy (2012) faz duas observações a respeito da bissexualidade, com base nas referências freudianas e lacanianas. Em primeiro lugar, destaca que Lacan chamou de "bissexualidade fantasmática do sujeito histérico" aquela na qual o sujeito identifica-se como homem para tentar responder ou questionar a feminilidade, tal como Freud nos mostrou por seus casos clínicos. A segunda diz respeito ao aforismo "não há relação sexual”, que nos ajuda a entender que não há completude entre os dois modos de gozo, o fálico e o feminino. Assim, a sexuação formaliza a impossibilidade da relação entre dois gozos, não se confundindo com as identificações e práticas sexuais. Se estas podem adotar diversas configurações na vida de um sujeito, elas só podem ser decifradas na singularidade de cada caso. 
O imperativo de gozo e o ideal de apagamento das diferenças entre os gêneros sexuais são traduzidos pelas seguintes frases recolhidas nas redes sociais da internet por adolescentes do sexo feminino: "Eu sou bi e acho que todo mundo é", "Qualquer tipo de amor vale a pena", "Não importa o sexo do parceiro, o importante é o amor", "Sou bi, e daí?", "Não preciso fazer uma escolha, e viva a liberdade..." "Não sou preso a categorias, não tentem me definir, defendo o amor e o sexo, livres".

Para se localizarem como homem ou mulher na cultura, os adolescentes fazem uso dos semblantes. Lacan, em $A$ significação do falo (1960), destaca a função de véu do falo. $\mathrm{O}$ autor salienta que o falo só pode desempenhar a sua função enquanto velado. Ele é o significante dessa própria Aufhebung (suspensão), que ele inaugura por seu desaparecimento. Segundo Lacan (1960), o demônio do Aidos (Sham), ou seja, do pudor, "surge no exato momento em que o falo é desvelado" (se referindo à célebre pintura da Villa de Pompeia) (p. 699). O falo, como significante do desejo, ordena as relações entre os sexos, em torno de um ser e de um ter que se lançam campo do "parecer".

Em De um discurso que não fosse semblante, Lacan (1971/2009) comenta que nada nos permite abstrair as definições de homem e mulher da experiência falante completa. A questão da identidade de gênero é da ordem dos semblantes. "Para o menino, na idade adulta, trata-se de parecer-homem" (p. 31). "Desse parecerhomem, um dos correlatos essenciais é dar sinal à menina de que se o é" (p. 31). E, mais à frente, acrescenta: "A identificação sexual não consiste em alguém se acreditar homem ou mulher, mas em levar em conta que existem mulheres, para o menino, e existem homens, para a menina” (p. 33).

O semblante consiste em fazer crer que há algo ali onde não há. Para a questão sobre o que é uma verdadeira mulher, Miller responde que é aquela que não tem e faz algo com esse não ter. Ao fazer algo com o "nada", isso tem efeitos no real. O semblante é, por excelência, máscara. O nome comum da identificação é a máscara, que é, fundamentalmente, máscara de nada (Miller, 2012, p. 65). Assim, as mulheres mantêm uma relação essencial e mais próxima com o nada. Freud nos mostrou que uma das particularidades psíquicas da maturação feminina é o pudor. O pudor tem a função essencial de velar a ausência do órgão genital. Mas, ao mesmo tempo em que vela a ausência, ele a constitui como algo. Ao velar, se cria, faz nascer, faz surgir (Miller, 2012). O pudor faliciza o corpo. O véu do pudor pode dar valor fálico a qualquer parte do corpo.

A partir das duas posições na partilha dos sexos, Miller diferencia a mulher que se constitui do lado do ter daquela que se constitui do lado do ser. Diante do encontro com o real do sexo, a jovem adolescente pode se posicionar 
preferencialmente do lado do ter ou do lado do ser. Ao se posicionar do lado do ser, assume sua falta a ter. É por reconhecer sua falta a ter que consegue ser o falo, o que falta aos homens (Miller, 2012, p. 73). Essa é a posição feminina. Ao assumir o menos, assume também os semblantes que jogam com o menos.

Como adverte Miller (2012), o ressentimento pela ausência de um significante feminino e a necessidade de se constituir um artifício fálico para recobrir a falta levam muitos adolescentes a buscar a solução histérica, uma solução do lado do ter. As comunidades sobre o feminino nas redes sociais funcionam com base na lógica da identificação. As redes sociais servem como veículos de identificação hoje. Toda a dinâmica das identificaçooes passa pelo sistema significante e, portanto, reinscreve o feminino do lado fálico, do lado do ter. A igualdade se dá pela via da lógica fálica.

Diante da ausência de um significante no inconsciente que defina o que é ser mulher, e ainda, diante do ideal de apagamento das diferenças sexuais na Contemporaneidade, as adolescentes buscam, através das ofertas de identificação na rede, uma forma de se localizarem na partilha dos sexos. $\mathrm{O}$ repúdio à diferença sexual, sustentado pelo ideal social de igualdade entre os sexos, que se manifesta por meio da defesa do bissexualismo, esconde, entretanto, um rechaço à castração.

Para Zucchi e Santos (2006), a anatomia não é o destino, mas o fundamento da sexuação. Para cada sujeito, há um destino, um sentido a dar à sua anatomia, e o gozo daí derivado não é equivalente a qualquer outro. Para a autora, alguns grupos sociais, como o Queer, preconizam que a identidade sexual é da ordem de um excesso, que não remete a nenhum real específico. $\mathrm{O}$ grupo recusa o real da diferença anatômica e busca a desconstrução de todos os semblantes identitários. No entanto esse processo de desconstrução, enquanto não remete ao real (pois tudo é semblante), acaba por validar todos os semblantes. Os jovens defendem a ideia de um sujeito "não identificado", plástico a qualquer modo de gozo, mas obtém, como efeito inverso, uma multiplicação de identidades.

\section{CONCLUSÃO}

A condição feminina requer, por um lado, o uso dos semblantes fálicos, mas, por outro, exige saber operar com o vazio da castração, com a dimensão real do gozo. Existem diferentes modalidades de identificação nas redes sociais da internet. Todas as soluçôes buscadas no campo das identificaçôes estão referidas à lógica fálica e, portanto, não abordam o feminino. Fica então a questão: existiria uma diferença entre a identificação com o grupo das lésbicas, das bissexuais, das "meninas-femininas" ou das "patricinhas"? 
Tendo em vista as duas modalidades de gozo descritas por Lacan, todas as respostas do lado da identificação estão situadas dentro da mesma lógica fálica, que é masculina, que implica numa tentativa de se esquivar do feminino, como gozo indizível. Uma "patricinha" pode se reconhecer como pertencente ao "gênero feminino" e se apoiar nos objetos de consumo ligados ao corpo como uma tentativa de construir uma categoria supostamente feminina, mas, na verdade, essa é uma solução que evita o feminino.

Todas as soluções no campo das identificações são inconsistentes, pois não respondem ao que é ser mulher no inconsciente. No entanto o declínio do Ideal e a proliferação de $S 1$ como nomes de gozo, que impõem modalidades de gozo comum a todos, torna as identificações mais inconsistentes. Além disso, a identificação com o significante "bissexual" não pode ser tomada como apenas uma das modalidades de identificação hoje. Ela aponta para o descrédito nos significantes utilizados para delimitar as diferenças entre o homem e a mulher. Trata-se de uma tentativa de se abolirem os alicerces da identificação sexual, apagando qualquer diferença entre os gêneros sexuais, como uma recusa do sujeito em fazer uma eleição sexual.

Esse ideal de igualdade serve ao discurso capitalista, que promete ao sujeito o acesso direto ao gozo, um gozo absoluto, sem perdas, ou seja, a ilusão de eliminação da castração, sustentada pela ideologia do consumo. Nas redes sociais pesquisadas, as adolescentes defendem a livre experimentação, sem restrições, do próprio corpo e dos corpos dos parceiros, de ambos os sexos, visando a alcançar um gozo pleno.

A diferença sexual não está puramente no campo simbólico, pois ela está referida ao que não se simboliza. $\mathrm{O}$ reconhecimento da castração leva o sujeito a uma tentativa de circunscrever a diferença sexual pela via significante. Pelas identificações com os significantes da cultura, o jovem está tentando dizer da diferença e, ao mesmo tempo, tentando anulá-la. O gozo não todo fálico é o núcleo central de toda posição sexual, experimentado como estranho e indizível, inerente a todo sujeito. A irrupção desse gozo é o encontro com o real do sexo, que acontece na puberdade. A sexualidade é uma tentativa de simbolizá-lo. O real do sexo é o buraco, o sem sentido, mas que somente pode ser abordado pela via dos semblantes, ou seja, pela articulação do imaginário com o simbólico. As identificaçóes permitem ao sujeito adolescente um tratamento simbólico ao real do gozo, por sua inserção no universal. Mas a produção propriamente singular dispensa o recurso às identidades sexuais e envolve a transmissão de um saber fazer com o gozo que escapa às referências fálicas. 
Para além das várias máscaras identificatórias que buscam definir os gêneros sexuais, a psicanálise sustenta a existência de uma diferença irredutível entre os sexos, que aponta para a impossibilidade da relação sexual, com a qual todo sujeito deve se haver. A diferença radical do Outro sexo é o feminino. Como destaca Fuentes (2012), a diferença sexual não é nem a anatomia nem o gênero. Este, como uma norma simbólica, fixa a identidade do sujeito. A noção de sexuação permite a Lacan precisar o que está em questão na diferença sexual. Como há uma disjunção entre o real e o simbólico, as identificações sexuais são infinitas, assim como são infinitas as práticas discursivas. Todos os significantes no campo da identificação sexual surgem como respostas ao impossível de simbolizar, o feminino. No entanto não podemos desprezar qualquer tentativa de simbolizar a diferença sexual, abolindo definitivamente as diferenciações de gênero que orientam o sujeito no campo das identificaçóes. Por outro lado, não se trata de multiplicar indefinidamente as formas de nomeação e classificação dos modos de gozo. Não vivemos num universo puramente simbólico. O real como impossível afeta a todos. A diferença sexual anatômica tem efeitos sobre o sujeito. O que importa é reconhecer como essa diferença é subjetivada por cada um e a escolha inconsciente que o sujeito faz do sexo, tendo em vista as duas formas distintas de tratamento do impossível.

$\mathrm{Na}$ contramão do ideal social de igualdade entre os sexos, a psicanálise oferece uma saída ética ao sujeito, pela via do reconhecimento da diferença, da localização do gozo estranho e opaco que não se submete à norma fálica, buscando, no caso a caso, a solução singular para lidar com o impossível de simbolizar. 


\section{REFERÊNCIAS}

Agamben, G. (2009). O que é o contemporâneo? e outros ensaios. In V. N. Honesko (Trad.). Chapecó: Argos.

Bardin, L. (2009). Análise de conteúdo. Lisboa: Edições 70.

Bauman, Z (2004). Amor líquido: sobre a fragilidade dos laços humanos. Rio de Janeiro: Jorge Zahar.

Brodsky, G. (2011a, março). Cinco decorrências da nova ordem simbólica para a direção do tratamento. Opção Lacaniana, 59, 3-5.

Brodsky, G. (2011b). Epidemias actuales y angustia. La clínica psicoanalitica. Córdoba: CIEC. (Grulla, 6).

Brousse, M. H. (2001). Las femeniedades: el outro sexo entre metáfora y suplência. In J. A. Miller, (Org.), Del Edipo a la sexuación. (pp. 55-62). Buenos Aires: Paidós.

Cottet, S. (1988). Puberdade catástrofe: transcrição 4. (101-106) Salvador: Fator.

Freud, S. (1905/1974). Três ensaios sobre a teoria da sexualidade. In J. Salomão (Trad.), Obras completas. (Vol. 7, pp. 118-230). Rio de Janeiro: Imago, 1974. (Publicado originalmente em 1905).

Freud, S. (1924/1974). A dissolução do complexo de Édipo. In J. Salomão (Trad.), Obras completas. (Vol. 19, pp. 215-224). Rio de Janeiro: Imago, 1974. (Publicado originalmente em 1924).

Fuentes, M. J. S. (2012). As mulheres e seus nomes: Lacan e o feminino. Belo Horizonte: Scriptum.

Godoy, C. (2012). Bissexualidade. In M. Antelo, (Org.), Mulheres de hoje: figuras do feminino no discurso analítico. (pp. 51-54). Petrópolis: KBR.

Harvey, D. (1992). Condição pós-moderna. São Paulo: Loyola.

Hassan, I. (1985). The culture of postmodernism. Theory, Culture and Society, 2(3), 119-131.

Jencks, Charles, (1989). What is post-modernism? London: Acadeiny Press.

Kehl, M. R. (2007). Sobre ética e psicanálise. São Paulo: Companhia das Letras. 
Lacan, J. (1960/1998). A significação do falo. In V. Ribeiro (Trad.), Escritos. (pp. 692703). Rio de Janeiro: Jorge Zahar, 1998. (Publicado originalmente em 1960).

Lacan, J. (1970/ 2003). Radiofonia. In V. Ribeiro (Trad.), Outros escritos. (pp. 400447). Rio de Janeiro: Jorge Zahar, 2003. (Publicado originalmente em 1970).

Lacan, J. (1971/2009). O seminário, livro 18: de um discurso que não fosse semblante. Rio de Janeiro: Jorge Zahar, 2009. (Publicado originalmente em 1971).

Lacan, J. (1972-1973/1985). Letra de uma carta de amor. In O seminário, livro 20: mais, ainda. (pp. 105-120). Rio de Janeiro: Jorge Zahar, 1985. (Publicado originalmente em 1972-1973).

Lacan, J. (1973/2003). Televisão. In V. Ribeiro (Trad.), Outros escritos. (pp. 508-543). Rio de Janeiro: Jorge Zahar, 1988. (Publicado originalmente em 1973).

Lacan, J. (1974/2003). O despertar da primavera. In V. Ribeiro (Trad.), Outros escritos. (pp. 557-559). Rio de Janeiro: Jorge Zahar, 2003. (Publicado originalmente em 1974).

Laurent, E. (2007). A sociedade do sintoma: a psicanálise hoje. Rio de Janeiro: Contra Capa.

Laville, C. \& Dionne, J. (1999). A construção do saber. Belo Horizonte: UFMG.

Lima, N. L. (2003). Fascinio e alienação do ciberespaço: uma contribuição da psicanálise para o campo da educação. (Dissertação de Mestrado). Universidade Federal de Minas Gerais, Faculdade de Educação, Belo Horizonte.

Lima, N. L. (2009). A escrita virtual na adolescência: os blogs como um tratamento do real da puberdade, analisados a partir da função do romance. (Tese de Doutorado). Universidade Federal de Minas Gerais, Faculdade de Educação, Belo Horizonte.

Miller, J. A. M. (2012). Mulheres e semblantes. In H. Caldas, A. Murta \& C. Murta (Orgs.). O feminino que acontece no corpo. (pp. 49-90). Belo Horizonte: Scriptum.

Orlandi, E. P. (1999). Análise de discurso: princípios e procedimentos. Campinas: Pontes.

Pêcheux, M. (1990). Delimitações, inversões, deslocamentos. Cadernos de Estudos Linguísticos, 19, 7-24.

Santos, M. (2011). Por uma outra globalização: do pensamento único à consciência universal. Rio de Janeiro: Record. 
Zucchi, M. A. \& Santos, T. C. (2006). O fantasma e o real: sobre a desigualdade entre os sexos. Psicologia Clínica, 18(2), 109-123. Recuperado a partir de http:// www.scielo.br/scielo.php?pid=S0103-56652006000200009\&script=sci_ arttext. 